\title{
O culto e o cultivo da misericórdia: a partir da pessoa e da práxis de Jesus de Nazaré
}

\author{
The cult and the practice of mercy: \\ from the person and the praxis of Jesus of Nazareth
}

Vitor Galdino Feller

\section{Resumo}

O artigo oferece pistas para continuar a praticar a misericórdia, como foi proposto pelo papa Francisco no Ano da Misericórdia, resgatando-a como o verdadeiro culto ao Pai, ensinado e praticado por Jesus de Nazaré. Examina a relação entre justiça e misericórdia, demonstrando que os últimos papas vêm propondo a misericórdia como um passo além da justiça. A misericórdia é o máximo que o ser humano pode praticar, porque por ela acontece a doação do que é meu e até de minha vida pelo bem do próximo. Apresenta a pessoa e a práxis de Jesus, mostrando que tudo nele transbordava misericórdia. Nesse sentido, importa voltar à proposta jesuânica da misericórdia como novo culto, que supera a justiça dos fariseus. A misericórdia que Jesus realiza é um ato de obediência à vontade de Deus, é o verdadeiro culto que agrada a Deus. Daí a necessidade de fazer da misericórdia o princípio gerador da vida eclesial e social. A misericórdia supõe e supera a justiça, e, destarte, entra nesse mundo que lhe parece tão refratário, fermentando-o com uma nova proposta ética. Mas a misericórdia também vem antes da justiça, enquanto em sua singeleza e sua parcialidade, enfrenta as ideologias e idolatrias que dominam a atualidade.

Palavras-chave: Misericórdia. Justiça. Culto cristão. Jesus de Nazaré. 


\begin{abstract}
The article proposes keys to go ahead practicing mercy, as proposed by Pope Francis in the Year of Mercy, presenting it as the true worship to the Father, as taught and practiced by Jesus of Nazareth. It goes through the relationship between justice and mercy, and reveals that the last popes proposed mercy as the further step of justice. Mercy is the maximum that the human being can practice, because the donation of what is mine and even my life in favor of others becomes real when there is mercy. It underlines that in the person and the praxis of Jesus, everything in Him was full of mercy. Indeed, it is important to return to the proposal of Jesus' mercy as the new worship, which exceeds the justice of the Pharisees. The mercy fulfilled by Jesus is an act of obedience to the will of God, and the true worship that pleases Him. Hence it is of great significance to have the Mercy as the generative principle of ecclesial and social life. Mercy supposes and surpasses justice, and thus, it enters into this world, that seems so resistant, fermenting it with a new ethical proposal. But mercy also comes before justice, while in its simplicity and partiality, it faces the ideologies and idolatries that dominate our present time.
\end{abstract}

Keywords: Mercy. Justice. Christian worship. Jesus of Nazareth.

\title{
Introdução
}

Terminado o Jubileu Extraordinário da Misericórdia, convém perguntarse sobre sua recepção e sua continuidade. Em que medida o Ano da Misericórdia mexeu com nossas mentalidades e práticas? Como exercer a misericórdia, visando a instauração de uma nova civilização, o mundo novo querido por Deus, o Reino de Deus pregado por Jesus de Nazaré, em que todos tenham vida em abundância (Jo 10,10)?

Depois de um item que trata da relação entre justiça e misericórdia, demonstrando que o magistério da Igreja, através dos últimos papas, vem propondo a misericórdia como um passo além da justiça, o presente artigo trabalha a proposta jesuânica do culto ${ }^{1}$ da misericórdia, um novo culto que supera a justiça dos fariseus. Em seguida, apresenta a pessoa e a práxis de Jesus

\footnotetext{
${ }^{1}$ A palavra "culto", usada no título e ao longo do texto, quer expressar elã, tendência ou atitude, com caráter religioso prático, que venera, privilegia e exalta a misericórdia.
} 
pela ótica da misericórdia, mostrando que do início ao fim de sua vida, tudo em Jesus respirava e transbordava misericórdia. Trata-se, depois, da misericórdia como princípio gerador da vida eclesial e social. Reflexões sobre o culto e o cultivo da misericórdia concluem o artigo. Primeiramente, apresenta-se a misericórdia para além da justiça, com passos importantes para sua prática em nossos tempos e, depois, a misericórdia aquém e antes da justiça, com características que ressaltam a singeleza e a parcialidade da misericórdia em relação com ideologias e idolatrias que dominam nossa atualidade.

$\mathrm{O}$ artigo pretende oferecer pistas para continuar a praticar a misericórdia, conforme proposto pelo papa Francisco no Ano da Misericórdia, resgatando-a como o verdadeiro culto a Deus-Pai, ensinado e praticado por Jesus de Nazaré, a ser cultivado na entrega da vida em favor do próximo.

\section{A relação entre justiça e misericórdia}

A cultura ocidental sempre insistiu na justiça como base para a instauração de uma nova sociedade e, mesmo, de uma nova civilização. Todas as democracias põem a justiça como condição para a convivência entre as pessoas, as classes, os povos e as nações. Justiça social é uma categoria filosófica e ética presente na reflexão teórica e nas propostas práticas do Ocidente desde os tempos da cultura clássica greco-romana, passando pela cultura medieval cristã, até os inícios da modernidade e os tempos atuais.

O papa João Paulo II, em sua encíclica Dives in Misericordia (DM), dá um passo adiante. Ensina que a misericórdia deve estar além da justiça, sobretudo quando esta se resigna ao mínimo e à acomodação do já alcançado.

A justiça por si só não basta, e (...) pode levar à negação e ao aniquilamento de si mesma, se não se permitir àquela força mais profunda, que é o amor, plasmar a vida humana nas suas várias dimensões (DM, 12).

O papa Bento XVI, em sua encíclica Caritas in Veritate (CV) sobre o desenvolvimento humano integral na caridade e na verdade, ao falar da justiça como princípio fundamental da Doutrina Social da Igreja, assim relacionou caridade - outro nome para misericórdia - e justiça:

A caridade supera a justiça, porque amar é dar, oferecer ao outro do que

é 'meu'; mas nunca existe sem a justiça, que induz a dar ao outro o que 
é 'dele', o que lhe pertence em razão do seu ser e do seu agir. Não posso 'dar' ao outro do que é meu, sem antes lhe ter dado aquilo que lhe compete por justiça. Quem ama os outros com caridade é, antes de mais nada, justo para com eles. A justiça não só não é alheia à caridade, não só não é um caminho alternativo ou paralelo à caridade, mas é 'inseparável da caridade', é-lhe intrínseca. (...) Por um lado, a caridade exige a justiça: o reconhecimento e o respeito dos legítimos direitos dos indivíduos e dos povos. (...) Por outro, a caridade supera a justiça e completa-a com a lógica do dom e do perdão $(\mathrm{CV}, 6)$.

Em sua bula Misericordiae Vultus (MV), de proclamação do Jubileu Extraordinário da Misericórdia, o papa Francisco indica que a misericórdia supera a justiça. "A misericórdia não é contrária à justiça", mas a ultrapassa. Entre outros autores bíblicos, o profeta Oseias mostra "a superação da justiça na linha da misericórdia", por meio da qual Deus oferece ao pecador nova possibilidade de arrepender-se e converter-se e começar uma nova vida. Em palavras luminosas o papa afirma:

A ira de Deus dura um instante, ao passo que a sua misericórdia é eterna. Se Deus se detivesse na justiça, deixaria de ser Deus. (...) A justiça por si só não é suficiente, e a experiência mostra que, limitando-se a apelar para ela, corre-se o risco de destruí-la. Por isso Deus, com a misericórdia e o perdão, passa além da justiça (MV, 21).

Os três últimos papas, cada um a seu modo, insistem na verdade cristã de que a caridade ou misericórdia supõe e supera a justiça. Na construção de uma nova sociedade, busca-se o mínimo, que é a justiça: dar ao outro, sobretudo ao pobre - como pessoa, classe, nação ou hemisfério - o que é dele, o que lhe pertence por seu ser ou agir, por sua dignidade ou ação, por seu mistério (o fato de ter sido criado à imagem e semelhança de Deus) e missão (o fato de lutar pela vida e, à custa de esforços pessoais e coletivos, conquistar direitos que se lhe tornam inalienáveis). Mas a justiça não foi ainda alcançada em todas as suas dimensões. A injustiça faz-se presente em todas as situações. Vem a pergunta: se não se alcança o mínimo, como pretender o máximo? Se não se alcança a justiça, como pretender a caridade, a misericórdia?

Consideramos que o ser humano não pode contentar-se com o mínimo, mas deve buscar sempre o máximo, pois é feito para algo mais, seja em termos racionais como afetivos. A razão sempre busca a compreensão e o alcance de 
todas as coisas, pois não pode acomodar-se ao mínimo. Uma razão filosófica ou ética, acomodada ao mínimo, não condiz com o ser humano, como nos lembra João Paulo II na encíclica Fides et Ratio (FR): "a cada uma destas manifestações (filosóficas), subjaz sempre vivo o desejo de alcançar a certeza da verdade e do seu valor absoluto" (FR, 24-27, aqui: 27). O afeto ou o coração sempre busca o máximo, pois o amor pretende a eternidade ("Amar alguém

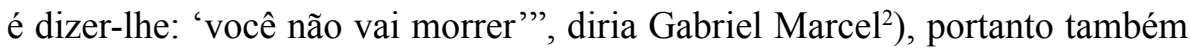
não pode acomodar-se ao mínimo. Acontece que vivemos numa época em que a razão está cansada e o coração está murcho. Daí as acomodações atuais ao mínimo e, não poucas vezes, nem a isto. A proposta cristã busca o máximo, como nos ensina o Senhor na parábola dos talentos: Deus não nos pede o mínimo, mas o máximo (Mt 25,14-30).

Se, por um lado, a misericórdia é o máximo, porque não é apenas a entrega do que pertence ao próximo, mas a doação do que é meu e até de minha vida pelo bem do próximo, por outro lado a misericórdia torna-se o mínimo, enquanto primeiro caminho a ser trilhado na busca e na realização da justiça. Nesse sentido, segundo o papa Bento XVI em sua encíclica Deus Caritas Est (DCE), pode-se dizer que Jesus Cristo e, a partir dele, a proposta cristã, não têm como primeira preocupação a justiça - missão própria do Estado -, mas a misericórdia, enquanto através dela vai purificando a razão, despertando forças morais e pavimentando a estrada da justiça (DCE, 29).

Ensina o papa Bento XVI: "A Igreja não pode nem deve tomar nas próprias mãos a batalha política para realizar a sociedade mais justa possível. Não pode, nem deve colocar-se no lugar do Estado" (DCE, 28). Mas pela fé, pela caridade, pela misericórdia, ela serve de força purificadora da razão e da justiça.

\section{O culto da misericórdia em Jesus de Nazaré}

"Ide, pois, aprender o que significa: 'Eu quero a misericórdia e não sacrificios'. De fato, não é a justos que vim chamar, mas a pecadores" (Mt 9,13). "Se tivésseis chegado a compreender o que significa, 'Eu quero misericórdia e não sacrificios', não condenaríeis inocentes” (Mt 12,7). Nas duas vezes em que Jesus se serve da palavra do profeta Oseias $(6,6)$ há uma relação de oposição à justiça dos chefes religiosos, que exclui pecadores

\footnotetext{
${ }^{2}$ MARCEL, G. Le Mystère de l'Être. Tome II: Foi et réalité. Paris: Aubier, 1981, p. 154.
} 
e condena inocentes. Outra é a justiça de Jesus, a justiça do Reino, a nova justiça - segundo a teologia mateana -, que é realização da vontade de Deus Pai. Essa nova justiça, que é "maior que a dos escribas e dos fariseus" (Mt 5,20), não consiste na aplicação mecânica da lei nem na prática sacrificialista de holocaustos no templo. Consiste em procurar e viver a vontade de Deus. Trata-se de um novo culto, a prática da misericórdia, já preconizado pelos profetas e, agora, levado até as últimas consequências por Jesus de Nazaré.

Assim se pode entender a

profunda mudança de perspectiva na passagem de Oséias a Cristo. Em Oséias, a expressão se refere ao homem, ao que Deus quer dele. Deus quer do homem amor e conhecimento, não sacrifícios exteriores e holocaustos de animais. Nos lábios de Jesus, a expressão se refere a Deus. O amor de que se fala não é o que Deus exige do homem, mas o que dá ao homem. 'Quero misericórdia e não sacrifício' significa: quero usar misericórdia, não condenar. Seu equivalente bíblico é a palavra que se lê em Ezequiel: 'Não quero a morte do pecador, mas que se converta e viva'. Deus não quer 'sacrificar' a sua criatura, mas salvá-la. Com esta observação, entende-se melhor também a expressão de Oseias. Deus não quer o sacrifício a 'todo custo', como se gostasse de nos ver sofrer; não quer tampouco o sacrifício realizado para alegar direitos e méritos diante dele, ou por um mal-entendido sentido do dever. Quer, ao contrário, o sacrifício que é requerido por seu amor e pela observância dos mandamentos. (...) A própria experiência cotidiana confirma isso. Não há amor sem sacrifício. Neste sentido, Paulo nos exorta a fazer de toda nossa vida 'um sacrifício vivo, santo e agradável a Deus'. ${ }^{3}$

Desse modo, o texto de Oseias ganha em Jesus dimensão mais ampla: a prática da misericórdia já é realização da justiça, enquanto inclui os pecadores, perdoa os inocentes e defende aos famintos (no caso, os discípulos, que arrancavam espigas em campo alheio) o acesso à alimentação. Trata-se da justiça do Reino, fundada em nova interpretação da Torah, feita por Jesus, que insiste, não nos preceitos religiosos, mas nos preceitos éticos, nas bemaventuranças, no Decálogo e nos grandes mandamentos do amor de Deus e do próximo. Nas controvérsias sobre o mandamento principal e na entrega

\footnotetext{
${ }^{3}$ CANTALAMESSA, R. "Que sacrifício e misericórdia Deus nos pede, segundo pregador do Papa". Disponível em: <https://pt.zenit.org/articles/que-sacrificio-e-misericordia-deusnos-pede-segundo-pregador-do-papa/>. Acesso em 24 de outubro de 2016.
} 
do mandamento novo, nas bem-aventuranças (Mt 5,1-12), na reinterpretação da Lei como nova justiça (Mt 5,21-48), na lista dos preceitos apresentada ao jovem rico (Mc 10,17-21), na parábola do juízo final (Mt 25,31-46) e em muitos outros lugares, são abundantes as prescrições sobre o modo de proceder com o próximo e mínimas as indicações sobre os deveres religiosos. ${ }^{4}$ Em Jesus, o culto a Deus revela-se como cultivo da misericórdia com o próximo.

A misericórdia que Jesus quer e realiza, antes de ser uma virtude (piedade, compaixão, amor, caridade) ou um sentimento que o leva a se compadecer da miséria alheia, um sentimento despertado diante da infelicidade do outro (pobre; marginalizado; estrangeiro; doente: cego, surdo, mudo, paralítico, leproso; mulher: viúva, prostituta; multidões etc.), é um ato de obediência à vontade de Deus, ou seja, à justiça que Deus quer com a prática de sua Lei e de seus mandamentos. A misericórdia é o verdadeiro culto que agrada a Deus.

Em Jesus, as mostras constantes de misericórdia, em sentimento e em obras, são demonstrações da justiça de Deus, isto é, da vontade de Deus de querer dar aos oprimidos o que lhes é de direito. É questão de justiça, de direito. Não o direito humano das leis sociais ou religiosas, mas o direito divino. É de direito divino que as multidões sejam saciadas, os doentes sejam curados, as mulheres sejam incluídas, os pobres sejam respeitados. Porque, por sua própria natureza, isto é, como criaturas de Deus, feitos à sua imagem e semelhança, esses direitos lhes são inerentes e inalienáveis. A prática de Jesus manifesta-se como misericórdia, mas supõe e supera a justiça.

As práticas de Jesus podem ser vistas nesta perspectiva. $\mathrm{O}$ anúncio do Evangelho aos pobres, o ensino a chamar a Deus de Pai, as expulsões dos espíritos malignos, as curas dos doentes, a acolhida e o perdão aos pecadores, o convite dos marginalizados ao banquete do Reino, o ensino fácil por meio de parábolas, a inclusão de mulheres, a saciação da fome das multidões... são práticas que, num primeiro olhar, revelam-se como atos de misericórdia, mas no fundo realizam a justiça de Deus e pavimentam o caminho para o fim da sociedade injusta e a instauração de uma nova sociedade, que seja sinal do Reino definitivo. ${ }^{5}$

\footnotetext{
${ }^{4}$ SOBRINO, J. Jesus, o libertador. I - A história de Jesus de Nazaré. Petrópolis: Vozes, 1994, pp. 246-249.

${ }^{5}$ SOBRINO, J. Jesus, o libertador, pp. 135-159.
} 


\section{Jesus Cristo: misericórdia do começo ao fim}

Em toda a sua vida, Jesus de Nazaré foi o rosto da misericórdia do Pai. O amor que vive na sua pré-existência com o Pai e o Espírito Santo na eternidade, ele o vive e expressa na sua pró-existência como misericórdia em favor dos seres humanos.

\subsection{Na pré-existência}

A misericórdia que Jesus é em pessoa e realiza em sua práxis revela o amor eterno que há entre ele e o Pai na eternidade, no fluxo eterno de amor unitivo e distintivo do Espírito Santo. ${ }^{6} \mathrm{O}$ amor eterno do Pai que se derrama sobre ele no ato da geração é a fonte de toda misericórdia que ele fará acontecer em sua vida terrena.

O amor das pessoas divinas não é misericórdia, pois não se trata de concessão, graça ou gratuidade em favor de alguém carente ou frágil. É um amor de necessidade, pois, embora de modo totalmente livre, as pessoas divinas se amam necessariamente.

O amor que existe na Trindade - e que constitui a Trindade - é natureza (para usar um termo que nos é acessível ainda que inadequado), não é graça; é amor, mas não misericórdia. (...) O Pai tem necessidade de amar para existir como Pai (...) (O Filho) necessita de ser amado e de amar para ser Filho. O Pai gera o Filho no Espírito Santo, ou seja, amando-O; o Pai e o Filho aspiram o Espírito Santo amando-se. ${ }^{7}$

Amor eterno de livre necessidade e não de gratuita misericórdia, o amor trinitário é, porém, a fonte absoluta da misericórdia que, através do Filho e do Espírito Santo, o Pai faz transbordar na criação e na história, na Igreja e na humanidade.

${ }^{6}$ FORTE, B. A Trindade como história. Ensaio sobre o Deus cristão. São Paulo: Paulinas, 1987, pp. $130-136$.

${ }^{7}$ CANTALAMESSA, R. O rosto da misericórdia. São Paulo: Paulus, 2016, p. 12 (parêntesis e itálicos do texto). 


\subsection{Na encarnação}

$\mathrm{Na}$ encarnação, dá-se um ato de transbordamento de Deus que, por pura misericórdia, além de nos criar, quis vir a nós fazendo-se humano em seu Filho Jesus Cristo. Assim, Jesus de Nazaré é o estuário da misericórdia eterna do Pai ${ }^{8}$ já presente na obra da criação e, de modo processual e cada vez mais explícito, revelada na Primeira Aliança. "Deus amou tanto o mundo, que deu seu Filho único, para que todo o que nele crer não pereça, mas tenha a vida eterna" (Jo 3,16). Jesus é o rosto transparente e a prática transbordante da misericórdia do Pai. Nele a criatividade da misericórdia não encontra limites. "Deus, rico em misericórdia, pelo imenso amor com que nos amou, quando ainda estávamos mortos por causa dos nossos pecados, deu-nos a vida com Cristo. É por graça que fostes salvos" (Ef 2,4-5).

\subsection{No evangelho da infância}

No evangelho da infância, a pré-história da atividade de Jesus, que é "um evangelho in nuce, se desenvolve completamente sob o sinal da misericórdia de Deus". 9 Todos os relatos, seja os de Mateus seja os de Lucas, anunciam a misericórdia divina, já conhecida na história de Israel, mas que agora se revela totalmente nova, vinda do céu, virginalmente, e se dirige aos pobres e desprezados. Em Lucas, temos o Magnificat e o Benedictus. O Magnificat celebra o poder do Deus santo que se manifesta em sua misericórdia com os que o temem (temor reverencial e piedade filial) e conclui dizendo que Deus acolhe a Israel recordando-se da misericórdia prometida aos descendentes de Abraão. O Benedictus é um canto à misericórdia de Deus que se revela aos pais e faz ver a luz do alto aos que habitam nas trevas e nas sombras da morte. Todos os interlocutores dos relatos da infância, Maria e José, o casal Zacarias e Isabel, o pequeno João, os velhos Simeão e Ana, os pastores e, até mesmo, os magos, por serem estrangeiros, são pessoas simples e pobres a quem se revela, em primeira mão, a misericórdia divina.

${ }^{8}$ PÉREZ, G. "Misericordia". In: RAMOS, F. F. Diccionario de Jesús de Nazaret. Burgos: Monte Carmelo, 2001, pp. 831-839.

${ }^{9}$ KASPER, W. A misericórdia. Condição fundamental do Evangelho e chave da vida cristã. São Paulo: Loyola, 2004, p. 83. 


\subsection{No ministério público}

No seu ministério público Jesus ensina sobre a misericórdia, com sentenças claras: "Bem-aventurados os misericordiosos, porque alcançarão misericórdia" (Mt 5,7). O Reino de Deus é o prêmio para as obras de misericórdia feitas aos famintos e sedentos, peregrinos e nus, doentes e presos, com quem Jesus se identifica (Mt 25,31-46). "Misericórdia eu quero e não sacrifícios" (Mt 9,13; 12,7). Segundo Lucas, a perfeição da prática da Lei (Mt 5,48: "sede perfeitos como o vosso Pai celeste é perfeito"), que Jesus exige de seus discípulos, consiste na prática da misericórdia: "Sede misericordiosos como vosso Pai é misericordioso" (Lc 6,36). Os ensinamentos mais importantes da Lei, o direito, a misericórdia e a fidelidade, vêm em primeiro lugar na escala de valores do Reino.

Entre os grandes ensinamentos sobre a misericórdia estão as parábolas da misericórdia, características de Lucas: o filho pródigo (Lc 15,11-32), o bom samaritano (Lc 10,19-37), o rico Epulão e o pobre Lázaro (Lc 16,1930), o servo sem compaixão (Mt 18,23-35), o juízo final (Mt 25,31-46). Essas parábolas "servem para esclarecer a própria conduta de Jesus, interpretando-a como expressão da conduta do Pai celestial". ${ }^{10} \mathrm{O}$ que Jesus recebe do Pai e vê o Pai fazer (as obras do Pai: Jo 5,19), ele o faz em favor dos marginalizados. Por isso, nessas parábolas,

Cristo é o verdadeiro protagonista, simbolizado na figura sublime e central do pai compassivo e dadivoso, que pauta seu agir por uma bondade acolhedora, que do começo ao fim é capaz de tudo fazer para o bem de seus filhos: renegado não renega, rejeitado não rejeita, abandonado não abandona, acusado não acusa, pelo contrário, acolhe no seio da família e pratica a misericórdia. ${ }^{11}$

Jesus não apenas ensinou, mas praticou a misericórdia. "A solicitude pelos miseráveis e pelos pobres, pelos pequenos e pelos insignificantes de um ponto de vista humano é, deste modo, a quintessência da missão messiânica de Jesus". ${ }^{12}$ A misericórdia que pratica, ele o pede aos discípulos quando os envia

\footnotetext{
${ }^{10}$ KASPER, W. A misericórdia, p. 93.

${ }^{11}$ GONZAGA, W. "Um Cristo compassivo e misericordioso (Lc 15,11-31)". In: FERNANDES, L. A. Traços da misericórdia de Deus segundo Lucas. Santo André; Rio de Janeiro: Academia Cristã; PUCRio, 2016, pp. 92-112, aqui: p. 109.

${ }^{12}$ KASPER, W. A misericórdia, p. 87.
} 
em missão. Foi misericordioso com os pecadores (os publicanos e prostitutas, Levi, Zaqueu, a adúltera, Pedro, seus assassinos, o bom ladrão) e envia os discípulos a pregar "a conversão para o perdão dos pecados a todas as nações" (Lc 24,47). Foi misericordioso com os doentes e aflitos (curas em geral, em dia de sábado, a mulher encurvada, cegos, surdos, mudos, paralíticos, leprosos, endemoninhados) e, ao enviar os discípulos a toda cidade e lugar para onde ele mesmo devia ir, comanda: "curai os doentes que nela houver" (Lc 10,9). Foi misericordioso com as mulheres (a pecadora na casa de Simão, a adúltera, a hemorroíssa, a samaritana), cuja dignidade reconheceu e proclamou.

\subsection{Na paixão e morte}

Até o fim Jesus foi homem de misericórdia. "Tendo amado os seus que estavam no mundo, amou-os até o fim" (Jo 13,1). A pré-existência de Jesus desabrocha na sua pró-existência. ${ }^{13}$ "Foram justamente a sua mensagem e as suas obras de misericórdia que geraram oposição, que foram consideradas escandalosas e que acabaram por levá-lo até à cruz". ${ }^{14}$ Jesus continua sua obra de misericórdia, ofertando a própria vida em resgate de muitos, pela salvação de todos, perdoando seus algozes e prometendo o paraíso ao bom ladrão, entregando-se nas mãos do Pai e consumando sua grande obra de misericórdia.

\subsection{Na ressurreição}

Ao ressuscitar o seu Filho Jesus, o Pai exerce sua misericórdia com o Filho obediente, a vítima pascal, que pagou o preço da pregação e da instauração de seu Reino de amor e justiça. Na ressurreição, o próprio Jesus, crucificadoressuscitado, mostra o poder de sua misericórdia porque, ao trazer a morte para dentro de seu campo de vida, além de não fugir dela, a vence a partir de dentro, derrotando-a de maneira plena. É o que se entende com o escárnio de Paulo: "A morte foi tragada pela vitória. Onde está, ó morte, a tua vitória? Onde está, ó morte, o teu aguilhão?” (1 Cor 15,54-55). E poderia continuar: Tu foste tragada, devorada pela força da vida. No poder da misericórdia do Espírito Santo, laço de amor eterno entre o Pai e o Filho, a morte foi vencida. Aconteceu a morte da morte. Não a morte de Deus, mas a morte em Deus! ${ }^{15}$

\footnotetext{
${ }^{13}$ KASPER, W. A misericórdia, pp. 93-100.

${ }^{14}$ KASPER, W. A misericórdia, p. 93.

${ }^{15}$ FORTE, B. A Trindade como história, pp. 33-40.
} 
Na entrega misericordiosa do Espírito Santo, o que acontece no evento pascal não é "a morte obscura de Deus", não é o "incompreensível extinguir-se do Absoluto", mas "é a hora da morte em Deus", "o ato que se desenrola em Deus, o evento da história do amor do Deus imortal". ${ }^{16}$

É nesse sentido que o $2^{\circ}$. Domingo da Páscoa é celebrado também, por instituição do papa João Paulo II, como Domingo da Divina Misericórdia. É “o dia que o Senhor fez", "maravilha aos nossos olhos", o dia em que o Cristo, "a pedra que os construtores rejeitaram, ficou sendo a pedra principal" (S1 118,2225). Nele se cantam as misericórdias de Deus em favor do povo de Israel e, por antecipação e extensão, em favor do novo povo, o povo messiânico, que vive da vitória alcançada pelo Cristo que, em sua ressurreição, já derrotou o pecado, o mal e a morte.

\subsection{Na obra da redenção}

Porque, na sua misericórdia, Deus quer fazer também a justiça, Jesus vicariamente nos representa e carrega os pecados de todos, fazendo-se inclusive pecado (2 Cor 5,21), para destruir o pecado e a morte desde dentro.

Na paixão de Jesus, toda a imundície do mundo entrou em contato com o imensamente Puro, com a alma de Jesus Cristo e, desse modo, com o próprio Filho de Deus. (...) Nesse contato, a imundície do mundo é realmente absorvida, anulada, transformada por meio do sofrimento do amor infinito. Visto que no Homem Jesus está presente o bem infinito, agora, na história do mundo, está presente e ativa a força antagonista de toda a forma de mal; o bem é infinitamente maior do que toda a massa de mal, por mais terrível que esta se apresente". ${ }^{17}$

Ele não foge da realidade do pecado, da anti-misericórdia, da anti-justiça, mas leva a realidade do pecado em consideração, carrega essa realidade e encarrega-se dessa realidade, ${ }^{18}$ para transformá-la desde o seu interior e tornála, através do seu Corpo, que é a Igreja, uma grande obra de misericórdia e, por meio da misericórdia, uma obra de justiça que durará até o fim dos tempos.

Em toda a sua vida, as palavras e as obras de misericórdia de Jesus foram

\footnotetext{
${ }^{16}$ FORTE, B. A Trindade como história, pp. 36-37 (itálicos no texto).

${ }^{17}$ RATZINGER, J.- BENTO XVI. Jesus de Nazaré. Da entrada em Jerusalém até a ressurreição. São Paulo: Planeta, 2011, p. 209.

${ }^{18}$ SOBRINO, J. Jesus, o libertador, p. 59.
} 
expressão do verdadeiro culto que ele prestou e continua a prestar ao Pai. Não o culto de sacrifícios no Templo, mas o culto de sua própria vida, ele, o novo Templo, que em seu próprio corpo, encarnou-se, viveu, morreu e ressuscitou (Jo 2,21-22) para nos manifestar a misericórdia do Pai.

\section{A misericórdia, princípio gerador de vida eclesial e social}

Na bula Misericordiae Vultus e no conjunto de seus ensinamentos e práticas sobre a misericórdia, o papa Francisco não faz um discurso filosófico. E, ao contrário de outras categorias geradoras do passado (as categorias de ratio, de natureza, de verdade etc.), a misericórdia, de fato, não pertence ao vocabulário clássico da filosofia. Mais que uma fundamentação filosófica, o papa faz uma fundamentação sapiencial e crente. E não é por acaso que ele tenha indicado a misericórdia como a categoria geradora de uma adequada forma de vida cristã e eclesial. ${ }^{19}$ Como a esperança em Charles Péguy (18731914), ${ }^{20}$ a misericórdia é uma virtude aparentemente frágil, mas, na verdade, é forte e firme, por saber iniciar processos e semear começos.

Para o papa Francisco, a virtude aparentemente frágil é a misericórdia. Mas, na homilia da missa de início de pontificado, ela já havia advertido que a misericórdia - a bondade ou a ternura - é a virtude dos fortes. Referindo-se a São José, cuja festa se celebrava, diz:

"Não devemos ter medo de bondade, ou mesmo de ternura. A propósito, deixai-me acrescentar mais uma observação: cuidar, guardar requer bondade, requer ser praticado com ternura. Nos Evangelhos, São José aparece como um homem forte, corajoso, trabalhador, mas, no seu íntimo, sobressai uma grande ternura, que não é a virtude dos fracos, antes pelo contrário denota fortaleza de ânimo e capacidade de solicitude, de compaixão, de verdadeira abertura ao outro, de amor. Não devemos ter medo da bondade, da ternura!"’21

\footnotetext{
19 MORRA, S. Dio non si stanca. La misericordia come forma ecclesiale. Bolonha: EDB, 2015.

${ }^{20}$ PÉGUY, Ch. Le porche du mystère de la deuxième vertu. In: Les mystères de Jeanne d'Arc, II. París: Emile-Paul, 1911.

${ }^{21}$ FRANCISCO. "Homilia da missa de início do ministério petrino do bispo de Roma". Disponível em: <https://w2.vatican.va/content/francesco/pt/homilies/2013/documents/papafrancesco_20130319_omelia-inizio-pontificato.html>. Acesso em 21 de outubro de 2016.
} 
No mundo atual, cujo problema fundamental é "a ignorância, o encobrimento e o entorpecimento diante da inumanidade cruel" diante dos povos crucificados, a misericórdia torna-se o princípio gerador de vida nova na Igreja e na sociedade.

A misericórdia não é suficiente, mas é absolutamente necessária num mundo que faz todo o possível para ocultar o sofrimento e evitar que o humano seja definido a partir da reação a esse sofrimento. (...) Se a razão não se tornar - também - razão compassiva e se a teologia (e a pastoral, poderíamos acrescentar) não se tornar - também - intellectus misericordiae, tenho muito medo que deixaremos os povos crucificados abandonados em sua desgraça, com muitos argumentos e com muitas teologias. $^{22}$

\section{5. $O$ culto e o cultivo da misericórdia, para além da justiça}

Como poderá a misericórdia tornar-se o verdadeiro culto cristão e ser cultivada na prática dos fiéis e das comunidades, de modo a supor, realizar e superar a justiça, e, destarte, entrar no mundo da política e da economia, da cultura e da sociedade, um mundo que lhe parece tão refratário, e fermentá-lo com uma nova proposta ética?

Numa época de fragmentação e de complexidade, não se pede à comunidade cristã que perca tempo em escorar seu edifício decadente com suplementos de ativismo pastoral e conselhos moralistas. Pede-se, cada vez mais, que retorne ao essencial e que responda ao empobrecimento geral da vida com um ato extraordinário de amor. Só um amor misericordioso poderá ser a alma desse projeto cultural, a decisão fundamental com que os cristãos podem tornar crível a grande conversão à misericórdia para a qual nos convida este início de milênio. ${ }^{23}$

Alguns passos são importantes e urgentes no cultivo prático da misericórdia, a fim de que ela venha a tornar-se o núcleo do culto cristão.

${ }_{22}^{2}$ SOBRINO, J. O principio misericórdia. Descer da cruz dos povos crucificados. Petrópolis: Vozes, 1994, pp. 7-8.

${ }^{23}$ ALICI, L. "A misericórdia como profecia cultural". In: VIRGILI, Rosanna; CANCIAN, Domenico et al. Misericórdia. Face de Deus e da nova humanidade. São Paulo: Paulinas, 2006, p. 200. 
Todos eles convergem para a volta às fontes, o retorno ao essencial, que é a pessoa e a práxis de Jesus de Nazaré: ${ }^{24}$

1. Tratar a misericórdia como dom e não como sentimento. A misericórdia alia-se ao mistério da gratuidade que envolve o ser humano por inteiro e responde ao sentido de limitação e incompletude que nos domina. A cultura narcisista, que pretende - mas não consegue - ocultar essa realidade de incompleteza, insiste na lógica do ter e do poder e não do acolher e do ser, a lógica do cálculo e do lucro e não a do dom e da graça. Em Jesus de Nazaré, ao contrário, pela prática permanente da misericórdia, tudo foi pura gratuidade, até a expressão máxima da entrega da própria vida.

2. Viver a misericórdia como virtude ética, síntese de compaixão e de beneficência, de paixão e de ação, portanto, nos sentidos passivo e ativo. A misericórdia deixa-se tocar pela miséria alheia, para carregá-la consigo e, se possível, superá-la, transformando o mal em bem. Abaixa-se para arrancar o outro de sua condição miserável, rebaixa-se para elevar (como na quênose de Cristo: Fl 2,6-11). Não promove nem a exaltação do poder das ideologias e de sua força de libertação (como se fez na modernidade), nem o encantamento com o pensamento débil e com a impotência divina (como se faz na pósmodernidade).

3. Casar a misericórdia com a justiça, de modo que aquela não se torne somente ato pessoal, assistencial e caritativo, mas adquira, com a justiça, a dimensão pública, social e profética. Pois, pela misericórdia se pode dilatar os horizontes de bem comum e de justiça social, ao mesmo tempo em que se acolhem e resgatam as vítimas das violências.

Pela sua capacidade de instaurar uma relação direta com o outro, em sua individualidade ferida e humilhada, a misericórdia permanece eminentemente como virtude pessoal, não, porém, privada, porque a promoção da pessoa é ato público por excelência, que possui uma incidência social e cultural que só se consegue encarnar-se em um ethos permeável às instâncias da dedicação e do perdão. ${ }^{25}$

4. Exercer a misericórdia forçando-a na dimensão da justiça. Atitudes pessoais e/ou grupais radicais, até mesmo formalmente ilegais, de misericórdia, podem abrir horizontes para a autêntica justiça. É o que se constata na pessoa

\footnotetext{
${ }^{24}$ Para os próximos itens, ver: ALICI, L. “A misericórdia como profecia cultural”, pp. 200-206.

${ }^{25}$ ALICI, L. “A misericórdia como profecia cultural”, p. 204.
} 
e práxis de Jesus de Nazaré, cuja ação radicalmente contrária às expressões religiosas da época, centradas no culto da Lei e do Templo, abriu espaços para novas percepções e práticas sociais e políticas. É o que também se verifica, na história da humanidade, onde pessoas e grupos com atitudes proféticas e ousadas, obedientes a Deus e fiéis à sua consciência, ainda que em desobediência das leis humanas, foram abrindo caminho para práticas reivindicativas e promotoras de direitos humanos e sociais.

5. Evidenciar o caráter diferencial da misericórdia em sua relação com a justiça. Talvez seja ousado dizer que Jesus foi mais misericordioso do que justo. De qualquer modo, mais do que preocupado com questões sociais e políticas, ele agiu em nome da misericórdia. A partir dele, fica explícito o que já se revelara na Primeira Aliança: "o nome de Deus é misericórdia". ${ }^{26}$ Jesus de Nazaré, embora não sendo político no sentido comum do exercício de uma profissão entre outras, foi eminentemente político, pois agudizou os conflitos sociais de seu tempo, revelou a Deus com conceitos e práticas e valores significativos para o ser humano, foi condenado como agitador político. Mas tudo isso ele o exerceu a partir de sua fé em Deus-Pai e do anúncio do Reino desse Deus. Poder-se-ia dizer, a partir do culto divino da misericórdia e do cultivo humano dessa misericórdia. Foi, portanto, tanto mais político quanto mais religioso foi seu ministério: falar de um Deus-Pai misericordioso e pôr em prática a misericórdia divina no anúncio do Reino de vida, justiça e paz. ${ }^{27}$ É o que diz o papa Bento XVI na encíclica Caritas in Veritate $(\mathrm{CV})$ :

A 'cidade do homem' (onde impera, ou deveria imperar a justiça) não se move apenas por relações feitas de direitos e de deveres, mas antes e sobretudo por relações de gratuidade, misericórdia e comunhão. A caridade manifesta sempre, mesmo nas relações humanas, o amor de Deus; dá valor teologal e salvífico a todo o empenho de justiça no mundo (CV, 6).

\section{6. $O$ culto e o cultivo da misericórdia, aquém e antes da justiça}

De um lado, a misericórdia vem depois da justiça e a supera. Por outro lado, as mais das vezes, a misericórdia é culto a Deus e cultivo da caridade e

${ }^{26}$ FRANCISCO. O nome de Deus é misericórdia. Uma conversa com Andrea Tornielli. São Paulo: Planeta, 2016.

${ }^{27}$ SEGUNDO, J. L. O homem de hoje diante de Jesus de Nazaré II/I: Sinóticos e Paulo, história e atualidades. São Paulo: Paulinas, 1985, pp. 107-129. 
da fraternidade e, como tal, está aquém e vem antes da justiça e a prepara e a possibilita e a solidifica. "O amor e a misericórdia podem revelar-se fontes de criatividade nestes processos, a fim de que se possa avançar da forma o menos violenta possível até uma ordem justa, aceitável por todos os implicados". ${ }^{28}$

A misericórdia caracteriza-se por ser parcial, germinal, invisível, inclusiva, mística, tática, formativa e rebelde. Essas características, por sua vez, resumem-se na sua parcialidade em favor dos pobres e excluídos. ${ }^{29}$ No culto ao Deus das misericórdias e no cultivo da misericórdia com o próximo, alguns rostos da misericórdia vão configurando o rosto de Cristo, o rosto concreto e visível da misericórdia do Pai, expresso no rosto e na carne e na ação determinada de multidões de pobres e excluídos.

1. O rosto parcial da misericórdia. A misericórdia tem preferência pelos pobres. Está sempre relacionada aos últimos e excluídos e necessitados. Essa preferência pode ser vista como predileção, num sentido de aproximação, identificação e solidariedade. Mas também como parcialidade, no sentido de escolha radical pelo lado fraco da sociedade. A misericórdia toma partido, é parcial. Essa foi a marca que Jesus de Nazaré deu à misericórdia. Sem abandonar outras classes sociais, ele fez opção radical e parcial pelos pobres. Os evangelhos o mostram sempre ao lado dos pobres, dos doentes, das mulheres, dos estrangeiros, em atitude conflitiva com os donos do poder religioso e social.

Como realidade escatológica o reino de Deus é universal, nele podem entrar todos, embora nem todos de modo igual. Mas, diretamente, o reino de Deus é unicamente dos pobres. (...) Esta afirmação, tão evidentemente bíblica, mas tão dificilmente aceita (...) tem suas raízes no Antigo testamento, que faz desta parcialidade algo essencial. (...) A parcialidade do reino de Deus, portanto, não deveria estranhar. Se apocalipticamente Jesus acentua seu caráter escatológico e sua vinda iminente, profeticamente sublinha a parcialidade de Deus como Deus dos pobres..$^{30}$

2. O rosto germinal da misericórdia. A misericórdia começa com gestos pequenos e simples. Diz um provérbio africano, citado por Dom Moacyr Grechi na abertura do $12^{\circ}$ Encontro Intereclesial das Comunidades

\footnotetext{
${ }^{28}$ KASPER, W. A misericórdia, p. 235.

${ }^{29}$ SOBRINO, J. Jesus, o libertador, pp. 128-131.

${ }^{30}$ SOBRINO, J. Jesus, o libertador, pp. 128-129.
} 
Eclesiais de Base (CEBs), em Porto Velho (RO), em 2009: "Gente simples, fazendo coisas pequenas, em lugares pouco importantes, consegue mudanças extraordinários". Com efeito, muito do que hoje se considera base dos direitos humanos e sociais e, portanto, questão de justiça, surgiu germinalmente como obra de misericórdia: hospitais, colégios, presídios etc., que "são o sedimento institucionalizado de gestos proféticos de misericórdia, que hoje continuam a encontrar inúmeras formas de atualização". ${ }^{31}$

3. O rosto invisivel da misericórdia. Em linha geral, a misericórdia não se vê, não se faz ver, não faz alarde. É a virtude de quem atua ocultamente. "Tu, porém, quando deres esmola, não saiba tua mão esquerda o que faz a direita, de modo que tua esmola fique escondida. E o teu Pai, que vê no escondido, te dará a recompensa" (Mt 6,3-4). Quantas pessoas, entidades, movimentos, pastorais, ONGs etc. atuam de modo escondido, invisível. Milhares de voluntários e agentes sociais, religiosos ou não, atuam diuturnamente em favor dos mais necessitados, praticando obras de misericórdia, materiais ou espirituais, privadas ou comunitárias, na simplicidade do dia a dia, por meses e anos e décadas. É a misericórdia que vai aos poucos tornando-se visível, ganhando publicidade, envolvendo mais agentes, ganhando corpo. Nesse sentido, ela precede a justiça, na medida em que a sociedade a vai assimilando gratuidade dessas obras, até passar a reivindicá-las como se fossem direitos.

4. O rosto inclusivo da misericórdia. A misericórdia não é excludente, não faz seleção de pessoas; ao contrário, inclui a todos, sobretudo os marginalizados. O ministério público de Jesus de Nazaré, ainda que se fizesse marcar pela parcialidade em favor dos pobres, implicava um chamado a todos. Dos pobres, Jesus não pedia nada, a não ser conscientização, ou seja, tomada de consciência de sua dignidade de filhos de Deus e a fé de que a obra salvífica de Deus os havia escolhido com especial predileção. Dos ricos, Jesus pedia conversão, abandono da idolatria do dinheiro e da confiança nos bens terrenos, compaixão em favor dos pobres. Dos discípulos, Jesus pedia capacidade hermenêutica na percepção da realidade e dos acontecimentos, a fim de interpretá-los não de modo ingênuo e cristalizador do status quo, mas de um modo crítico, que os levasse ao profetismo, a tomar posição diante do duelo entre os deuses em questão - o Pai de Jesus e dos pobres contra os deuses produtores de morte dos adoradores religiosos. ${ }^{32}$ Ainda assim, Jesus

\footnotetext{
${ }^{31}$ ALICI, Luigi. “A misericórdia como profecia cultural”, pp. 205.

${ }^{32}$ SEGUNDO, J. L. O homem de hoje diante de Jesus de Nazaré, pp. 185-233.
} 
não excluía ninguém do chamamento ao Reino. Mas, diante das ideologias e práticas dissonantes nos quesitos "Deus" e "Reino de Deus", deixava claro a necessidade de mudança de mentalidade e prática. ${ }^{33}$

5. O rosto místico da misericórdia. Para o exercício da misericórdia fazse necessária muita abertura à graça de Deus, alcançada através da oração, vivida com paixão e elã, no cuidado atento das dimensões espirituais do ser humano. A pessoa que vive a misericórdia necessita abastecer-se da divina misericórdia. Ninguém dá o que não tem. Vida de oração, de retiro espiritual, de contato com as Escrituras, de unção no Espírito, de relação com o Pai das misericórdias... são práticas de Jesus de Nazaré imediatamente percebidas e apreendidas pelos discípulos. Por outro lado, quem oferece misericórdia não se preocupa só com a solução das carências materiais. Mais do que isso, aos necessitados oferece-se luz e sentido para a vida. Por isso, a misericórdia não se casa com o pelagianismo. O papa Francisco tem sido muito crítico do neo-pelagianismo que tem tomado conta do mundo de hoje e até das relações e instituições eclesiais. ${ }^{34}$ Confia-se demasiadamente no empenho, na eficácia e nas conquistas humanas. Talvez por isso seja tão difícil ser misericordioso!

6. O rosto tático da misericórdia. A misericórdia é simples como as pombas, mas esperta como as serpentes (Mt 10,16). Não é ingênua, nem imediatista. Tem uma dimensão articuladora, estratégica. Não atua de modo puramente assistencialista. Mas busca organizar e articular todas as ações, por pequenas que sejam, realizando reuniões e encontros inter-grupais, promovendo articulação inter-classes (ricos e pobres), envolvendo classes médias e altas (por meio do que podem oferecer, mediante suas profissões, voluntariado, ofertas materiais etc.), aproveitando-se do tempo livre dos aposentados etc. Em seu ministério público, Jesus foi um grande articulador. Sabia trabalhar com massas e minorias, diferenciando e valorizando pessoas e grupos (multidões, pobres, doentes, mulheres, apóstolos), identificando claramente seus opositores (chefes religiosos, como os fariseus, os saduceus e os sacerdotes, e chefes políticos, como Herodes e Pilatos). ${ }^{35}$

\footnotetext{
${ }^{33}$ SOBRINO, J. Jesus na América Latina. Seu significado para a fé e a cristologia. São Paulo; Petrópolis: Loyola; Vozes, 1985, pp. 144-179.

${ }^{34}$ FELLER, V. G. “A crítica do papa Francisco ao pelagianismo". Encontros Teológicos 30/1 (2015), pp. 51-71.

${ }^{35}$ WENZEL, J. I. Pedagogia de Jesus segundo Marcos, São Paulo: Loyola, 1997.
} 
7. O rosto formativo da misericórdia. A misericórdia não se contenta com o puro fazer. Ela favorece a busca do conhecimento, promove encontros de formação, a fim de que os pobres não se permitam serem usados como massa de manobra, por interesses ideológicos escusos, mas descubram meios próprios de articular sua própria revolução social. Não se faz revolução social com audiência de novelas, reportagens e noticiários dos meios de comunicação, com leitura de revistas de moda ou de pornografia. Mas com análises de conjuntura, com a leitura das Escrituras e de biografias de agentes sociais, pessoas que se opuseram a regimes de escravidão e opressão, santos que praticaram obras de misericórdia. Jesus de Nazaré chamava frequentemente à parte os seus discípulos e às vezes também as multidões para tempo de reflexão e formação, de revisão de vida, de retomada do processo de conscientização, de análise da realidade, de libertação pessoal e social.

8. O rosto rebelde da misericórdia. A misericórdia não é conformada, nem resignada, não se acomoda com a situação. É sempre anti: antimercado, anti-moda, anti-mídia. A misericórdia desenvolve e mantém aceso o espírito crítico diante desses sistemas que frequentemente se colocam a serviço das classes dominantes e mantêm o status quo da desigualdade social. Nas ações sociais paroquiais, nas pastorais sociais, nas ONGs, nos conselhos paritários de direitos etc., sempre há, ainda que de modo diferenciado, uma atitude de rebeldia, de inconformismo. Pessoas conformadas com a situação e com os sistemas político-econômicos de plantão terão muita dificuldade para serem misericordiosas, pois não se sentem incomodadas, feridas, machucadas. O exemplo de Jesus de Nazaré é claro. Ele agiu, viveu e morreu como rebelde. Não se conformou com a situação de abandono e exclusão da maioria da população de sua sociedade. Manteve-se 24 sobre 24 horas na rebeldia contra o messianismo triunfalista das multidões (que queriam fazê-lo rei), contra a escassez de inteligência dos discípulos (frequentemente repreendidos, como Tiago e João, que queriam dos primeiros lugares no Reino futuro), contra o legalismo dos fariseus, contra o sacrificalismo dos sacerdotes no Templo de Jerusalém. Essa atitude de rebeldia não era, porém, em Jesus, marcada por amargura e espírito cítrico, mas por permanente disposição para enfrentar o conflito e propor caminhos diversos e mais amplos de misericórdia. 


\section{Conclusão}

O Jubileu Extraordinário da Misericórdia não tinha como objetivo precípuo comemorar alguma data, celebrar algum evento, mas propunha-se a promover a prática da misericórdia. Mais que celebrar, praticar! Durante o Ano da Misericórdia procurou-se viver essa virtude nuclear do cristianismo. Terminado o jubileu, pergunta-se pela sua recepção e continuidade.

Na relação, frequentemente analisada, entre justiça e misericórdia, dá-se hoje um acento sempre maior a esta última. O magistério da Igreja, através do ensinamento dos últimos papas, propõe que se veja a misericórdia como um passo a mais além da justiça. A misericórdia é a virtude do próprio Deus, é o máximo que o ser humano pode praticar, porque não é apenas a entrega do que pertence ao próximo, mas a doação do que é meu e até de minha vida pelo bem do próximo. Mas ela torna-se o mínimo, enquanto primeiro caminho a ser trilhado na busca e na realização da justiça.

Nesse sentido, importa voltar à proposta jesuânica do culto da misericórdia, um novo culto que supera a justiça dos fariseus. A misericórdia que Jesus quer e realiza, mais que ser uma virtude ou um sentimento de compaixão diante da infelicidade do outro, é um ato de obediência à vontade de Deus, à justiça querida por Deus, pela prática de sua Lei e de seus mandamentos. A misericórdia é o verdadeiro culto que agrada a Deus.

Para viver esse culto, é preciso voltar à pessoa e à práxis de Jesus de Nazaré e captá-lo pela ótica da misericórdia. Do início ao fim de sua vida, tudo em Jesus respirava e transbordava misericórdia. Desde a encarnação, passando pela infância e pelo ministério público, até sua morte e ressurreição, tudo na vida de Jesus é expressão da misericórdia.

A misericórdia, virtude aparentemente frágil, é a rocha firme e forte que se estabelece como princípio gerador da vida eclesial e social. Ao contrário de outras categorias geradoras do passado, como razão, natureza, verdade etc., a misericórdia não pertence ao vocabulário clássico da filosofia. Ela pertence à ordem da reflexão sapiencial e crente. Não é por acaso que o papa a tenha indicado como a categoria geradora de uma adequada forma de vida cristã e eclesial

O culto e o cultivo da misericórdia mostram que ela vai além da justiça. $\mathrm{O}$ verdadeiro culto cristão, a ser cultivado na prática dos fiéis e das comunidades, supõe, realiza e supera a justiça, e, destarte, entra no mundo da política e da economia, da cultura e da sociedade, um mundo que lhe parece tão refratário, 
fermentando-o com uma nova proposta ética, com passos importantes para sua prática em nossos tempos.

O culto e o cultivo da misericórdia também mostram que ela está aquém e antes da justiça, com características que ressaltam sua singeleza e sua parcialidade em relação com ideologias e idolatrias que dominam nossa atualidade.

A misericórdia é o verdadeiro culto oferecido a Deus-Pai, ensinado e praticado por Jesus de Nazaré, a ser cultivado na entrega da vida em favor do próximo.

\section{Referências bibliográficas}

ALICI, L. "A misericórdia como profecia cultural". In: VIRGILI, Rosanna; CANCIAN, Domenico et al. Misericórdia. Face de Deus e da nova humanidade. São Paulo: Paulinas, 2006, pp. 183-206.

CANTALAMESSA, R. “Que sacrifício e misericórdia Deus nos pede, segundo pregador do Papa". Disponível em: <https://pt.zenit.org/articles/quesacrificio-e-misericordia-deus-nos-pede-segundo-pregador-do-papa/>. Acesso em 24 de outubro de 2016.

CANTAlAmESSA, R. O rosto da misericórdia. São Paulo: Paulus, 2016.

FELLER, V. G. "A crítica do papa Francisco ao pelagianismo". Encontros Teológicos 30/1 (2015), pp. 51-71.

FORTE, B. A Trindade como história. Ensaio sobre o Deus cristão. São Paulo: Paulinas, 1987.

FRANCISCO. O nome de Deus é misericórdia. Uma conversa com Andrea Tornielli. São Paulo: Planeta, 2016.

FRANCISCO. "Homilia da missa de início do ministério petrino do bispo de Roma”. Disponível em: <https://w2.vatican.va/content/francesco/ pt/homilies/2013/documents/papa-francesco_20130319_omelia-iniziopontificato.html>. Acesso em 21 de outubro de 2016.

GONZAGA, W. "Um Cristo compassivo e misericordioso (Lc 15,11-31)". In: FERNANDES, L. A. Traços da misericórdia de Deus segundo Lucas. Santo André; Rio de Janeiro: Academia Cristã; PUC-Rio, 2016, pp. 92-112. 
KASPER, W. A misericórdia. Condição fundamental do Evangelho e chave da vida cristã. São Paulo: Loyola, 2004.

MORRA, S. Dio non si stanca. La misericordia come forma ecclesiale. Bolonha: EDB, 2015.

PÉREZ, G. "Misericordia". In: RAMOS, F. F. Diccionario de Jesús de Nazaret. Burgos: Monte Carmelo, 2001, pp. 831-839.

RATZINGER, J.-BENTO XVI, Jesus de Nazaré. Da entrada em Jerusalém até a ressurreição. São Paulo: Planeta, 2011.

SEGUNDO, J. L. O homem de hoje diante de Jesus de Nazaré II/I: Sinóticos e Paulo, história e atualidades. São Paulo: Paulinas, 1985.

SOBRINO, J. Jesus na América Latina. Seu significado para a fé e a cristologia. São Paulo; Petrópolis: Loyola; Vozes, 1985.

SOBRINO, J. Jesus, o libertador. I - A história de Jesus de Nazaré. Petrópolis: Vozes, 1994.

SOBRINO, J. O princípio misericórdia. Descer da cruz dos povos crucificados. Petrópolis: Vozes, 1994.

WENZEL, J. I. Pedagogia de Jesus segundo Marcos, São Paulo: Loyola, 1997.

Vitor Galdino Feller

Doutor em Teologia Professor na Faculdade Católica de Santa Catarina (FACASC) Florianópolis / SC - Brasil E-mail: vitorfeller@arquifln.org.br

Recebido em: 19/01/2017

Aprovado em: 24/04/2017 